\title{
Geogenic organic carbon in terrestrial sediments and its contribution to total soil carbon
}

\author{
Fabian Kalks ${ }^{1}$, Gabriel Noren ${ }^{2}$, Carsten W. Mueller ${ }^{3,4}$, Mirjam Helfrich ${ }^{1}$, Janet Rethemeyer ${ }^{2}$, and \\ Axel Don ${ }^{1}$ \\ ${ }^{1}$ Thünen Institute of Climate-Smart Agriculture, Bundesallee 65, 38116 Braunschweig, Germany \\ ${ }^{2}$ Institute of Geology and Mineralogy, University of Cologne, Institute of Geology and Mineralogy, \\ Zülpicher Str. 49b, 50674 Cologne, Germany \\ ${ }^{3}$ Chair of Soil Science, School of Life Sciences, Technical University of Munich, Emil-Ramann-Strasse 2, \\ 85354 Freising-Weihenstephan, Germany \\ ${ }^{4}$ Department of Geosciences and Natural Resource Management, University of Copenhagen, \\ Øster Voldgade 10, 1350 Copenhagen K, Denmark
}

Correspondence: Fabian Kalks (fabian.kalks@ thuenen.de)

Received: 19 May 2020 - Discussion started: 5 June 2020

Revised: 18 May 2021 - Accepted: 27 May 2021 - Published: 6 July 2021

\begin{abstract}
Geogenic organic carbon (GOC) from sedimentary rocks is an overlooked fraction in soils that has not yet been quantified but influences the composition, age, and stability of total organic carbon (OC) in soils. In this context, GOC is the OC in bedrock deposited during sedimentation. The contribution of GOC to total soil OC may vary, depending on the type of bedrock. However, no studies have been carried out to investigate the contribution of GOC derived from different terrestrial sedimentary rocks to soil OC contents.

In order to fill this knowledge gap, $10 \mathrm{~m}$ long sediment cores from three sites recovered from Pleistocene loess, Miocene sand, and Triassic Red Sandstone were analysed at $1 \mathrm{~m}$ depth intervals, and the amount of GOC was calculated based on ${ }^{14} \mathrm{C}$ measurements. The ${ }^{14} \mathrm{C}$ ages of bulk sedimentary $\mathrm{OC}$ revealed that $\mathrm{OC}$ is comprised of both biogenic and geogenic components. The biogenic component relates to OC that entered the sediments from plant sources since soil development started. Assuming an average age for this biogenic component ranging from 1000-4000 years BP (before present), we calculated average amounts of GOC in the sediments starting at $1.5 \mathrm{~m}$ depth, based on measured ${ }^{14} \mathrm{C}$ ages. The median amount of GOC in the sediments was then taken, and its proportion of soil mass (g GOC per kg-1 fine soil) was calculated in the soil profile. All the sediments contained considerable amounts of GOC (median amounts of $0.10 \mathrm{~g} \mathrm{~kg}^{-1}$ in Miocene sand, $0.27 \mathrm{~g} \mathrm{~kg}^{-1}$ in Pleistocene loess, and $0.17 \mathrm{~g} \mathrm{~kg}^{-1}$ in Red Sandstone) compared with subsoil OC contents (between 0.53 and $15.21 \mathrm{~g} \mathrm{~kg}^{-1}$ ). Long-term incubation experiments revealed that the GOC appeared comparatively stable against biodegradation. Its possible contribution to subsoil OC stocks $(0.3-1.5 \mathrm{~m}$ depth) ranged from $1 \%$ to $26 \%$ in soil developed in the Miocene sand, from $16 \%$ to $21 \%$ in the loess soil, and from $6 \%$ to $36 \%$ at the Red Sandstone site. Thus, GOC with no detectable ${ }^{14} \mathrm{C}$ content influenced the ${ }^{14} \mathrm{C}$ ages of subsoil OC and may partly explain the strong increase in ${ }^{14} \mathrm{C}$ ages observed in many subsoils. This could be particularly important in young soils on terrestrial sediments with comparatively low amounts of OC, where GOC can make a large contribution to total OC stocks.
\end{abstract}




\section{Introduction}

On average, the world's soils store more than $50 \%$ of organic carbon (OC) in the subsoil below $30 \mathrm{~cm}$ depth (Batjes, 2014). This type of carbon is considered a highly stable carbon pool due to its apparently high ${ }^{14} \mathrm{C}$ ages (Mathieu et al., 2015; Schrumpf et al., 2013). However, another explanation for this could be the contribution of geogenic organic carbon (GOC), which is defined here as OC that originates from deposition during sedimentation and rock formation and may increasingly influence subsoil OC with depth (Graz et al., 2010; Kögel-Knabner et al., 2008; Schrumpf et al., 2013; Trumbore, 2009). GOC, in most cases, is devoid of ${ }^{14} \mathrm{C}$ and, thus, may lead to an overestimation of ancient OC sources, although a number of studies showed the importance of root-derived young OC inputs to subsoils (Angst et al., 2016; Crow et al., 2009). Therefore, GOC may significantly influence and affect the overall ${ }^{14} \mathrm{C}$ signal, particularly in OC-poor subsoils. Vindušková et al. (2015) investigated the contribution of GOC to soils in reclaimed mine soils and found GOC contributions to total soil OC of between $26 \%$ and $99 \%$. Furthermore, OC-rich sediments with contents of $2-7 \mathrm{~g} \mathrm{~kg}^{-1}$ (Hemingway et al., 2018) and 28$105 \mathrm{~g} \mathrm{~kg}^{-1}$ were also found. Frouz et al. (2011) investigated this with regard to the stability of OC in these sediments but no conclusion was reached about GOC contributions in soils. However, the impact of GOC on soils derived from sediments or sedimentary rocks with lower OC contents has not yet been investigated. Considering that approximately $65 \%$ of the continental Earth's surface is covered with sediments and sedimentary rocks (Amiotte Suchet et al., 2003), a potentially large fraction of soils could contain GOC that contributes to soil OC stocks, even though a large portion might be derived from recent sedimentation processes. There is not yet much literature about sediments containing only low amounts of OC. There are estimations that assume sandstones to be free of GOC (van der Voort et al., 2019), or, in contrast, there is a storage model that assumes generally high GOC amounts of $2.4 \mathrm{~g} \mathrm{~kg}^{-1}$ for all sandy deposits (Copard et al., 2007). Therefore, more information about the amount of GOC in sediments is needed.

To estimate the possible contribution of GOC to subsoil OC stocks, it is important to establish the amount of OC in sediments that comes from sedimentation (GOC) and to distinguish it from $\mathrm{OC}$ derived from current vegetation (biogenic OC). There are many soil- and substrate-specific factors that might influence the OC contribution from current vegetation to sedimentary $\mathrm{OC}$, such as potential rooting depth or pore distribution. No method has yet been established to allow a direct quantification of GOC in different soils or sediments, apart from promising methods to quantify the graphitic part of GOC in soils (Zethof et al., 2019). The only reliable approach for distinguishing between both sources is the use of ${ }^{14} \mathrm{C}$. Since the deposition of sediments mostly took place $>50000$ years BP (before present), they do not contain ${ }^{14} \mathrm{C}$, which has a mean half-life time of 5730 years (Libby, 1952). In addition, the $\delta^{13} \mathrm{C}$ values of OC in the sediments allow carbonaceous sources with $\delta^{13} \mathrm{C}$ values around $0 \%$ to be distinguished from organic sources with $\delta^{13} \mathrm{C}$ values $<-22 \%$. Thus, the use of both carbon isotopes could reveal whether the OC is a mixture of GOC and OC from vegetation that is less than 50000 years old.

One important question about the possible contribution of GOC in soils is whether the GOC is mineralised when it becomes part of the soil. As GOC resists degradation once it has been deposited, it can be assumed that it already exhibits a strong inherent recalcitrance. Nevertheless, this could also be due to a physical protection that prevents microbial accessibility. However, when it becomes part of the subsoil during soil development, this OC pool could be degraded by the infiltration of water, oxygen, fresh nutrients, and microorganisms. Direct microbial coal degradation has already been observed in incubation experiments on mine soils (Rumpel and Kögel-Knabner, 2002; Waschkies and Huttl, 1999) or shale bedrock directly exposed to the surface (Soulet et al., 2018). There has been no study to establish whether GOC is degradable in OC-poor sediments or sedimentary rocks, but it could differ since the amount of available OC can also drive microbial respiration (Colman and Schimel, 2013). Therefore, these sediments might contain fewer microorganisms that can be spatially separated from the GOC, which may hamper its respiration.

To the best of the authors' knowledge, there has only been one study by van der Voort et al. (2019) that has investigated the amount of GOC in soils. They estimated that GOC makes up around $80 \%$ of soil OC in a moraine-derived soil, suggesting that GOC's contribution to soil OC is large. However, apart from this study by van der Voort et al. (2019) on a very specific sediment, there have been no direct calculations of the amount of GOC in soils.

The aim of this study was to quantify GOC in different terrestrial sediments and a sedimentary rock and to investigate its stability in incubation experiments in order to make assumptions about its possible contribution to soil OC stocks in soil profiles at the same site. The main research questions were as follows: (i) what is the relationship between sedimentary and subsoil OC contents? (ii) Is OC in sediments ${ }^{14} \mathrm{C}$-free, and how much is really geogenic? (iii) Will sedimentary GOC be degraded? (iv) How much does GOC contribute to soil OC?

\section{Material and methods}

\subsection{Site description}

In total, three sites were selected with different sedimentary bedrock derived from a single geologic substrate that can be found close to the surface and is homogeneous down to $10 \mathrm{~m}$ depth. The sites represented one sedimentary rock and two soft sediments. The sedimentary rock was a 
sandstone (Solling Formation and Triassic) under European beech forest (Fagus sylvatica) $11.5 \mathrm{~km}$ northeast of Göttingen $\left(51^{\circ} 35.012^{\prime} \mathrm{N}, 10^{\circ} 3.960^{\prime} \mathrm{E}\right)$ and is referred to below as Red Sandstone. The soil is classified as a Folic Brunic Arenosol according to the World Reference Base for Soil Resources (WRB, 2006). The sediments were loessic deposits (Weichselian glacial) that have been under agricultural land use for the past decades, $30 \mathrm{~km}$ north of Göttingen $\left(51^{\circ} 48.101^{\prime} \mathrm{N}, 9^{\circ} 58.002^{\prime} \mathrm{E}\right)$, and referred to as loess. There are also terrestrial sandy deposits from the Miocene (Neogene; formerly named Tertiary) in a European beech forest $13 \mathrm{~km}$ southwest of Göttingen $\left(51^{\circ} 28.673^{\prime} \mathrm{N}\right.$; $\left.9^{\circ} 45.323^{\prime} \mathrm{E}\right)$ referred to as Miocene sand. The respective soils have been accordingly classified as a Haplic Luvisol and a Dystric Chromic Arenosol. The sediments at the loess site were deposited between the last glacial and interglacial periods between 115000 and 400000 years BP, according to Jordan and Schwartau (1993). To the best of the authors' knowledge, these forest sites have never been under agricultural use. The associated soils are classified as a Luvisol and a Cambisol, respectively. Mean annual air temperature and precipitation were $9.2^{\circ} \mathrm{C}$ and $647 \mathrm{~mm}$ (1981-2010), according to the nearby weather station that covers all three sites.

\subsection{Sampling and sample preparation}

In total, two $10 \mathrm{~m}$ long sediment cores with a diameter of $15 \mathrm{~cm}$ were drilled at each site in April 2017. For the soft sediments (loess and Miocene sand), drilling was conducted as percussion drilling, and for the hard sediment (Red Sandstone), cable core drilling was conducted, with water as the flushing solution. The replicates per site were drilled approximately $10 \mathrm{~m}$ apart. The sampled cores were subdivided into $1 \mathrm{~m}$ increments. For further chemical analysis, material was taken from a depth of $85-95 \mathrm{~cm}$ for each $1 \mathrm{~m}$ increment, and the outer $5 \mathrm{~cm}$ removed to avoid possible contamination. Thus, the increment from 1-2 $\mathrm{m}$ for example, was represented by a sample from a $1.85-1.95 \mathrm{~m}$ depth.

A sample from each depth increment (1-2, 2-3, 3-4, 4$5,5-6,6-7,7-8,8-9$, and 9-10 m) for chemical analysis was oven-dried at $60^{\circ} \mathrm{C}$ and sieved to pass $2 \mathrm{~mm}$. The Red Sandstone samples were crushed with a hammer before being dried and sieved. Additionally, approximately $1 \mathrm{~m}$ deep soil profiles were dug, and soil samples taken from the different classified layers to obtain corresponding soil parameters (Fig. 1). For the determination of $\mathrm{OC}$ and ${ }^{13} \mathrm{C}$, samples were ground in a planetary ball mill.

\subsection{Chemical analysis and calculations}

In total, three aliquots of each sieved sample were analysed by dry combustion for total $\mathrm{C}$ and total $\mathrm{N}$ content (TruMac CN, LECO, St Joseph, MI, USA). Samples with a $\mathrm{pH}$ value of $>6$ (measured in $0.01 \mathrm{~mol} \mathrm{~L}^{-1} \mathrm{CaCl}$ ) were analysed for carbonates after the sample was ignited for $16 \mathrm{~h}$ in a muf- fle kiln at $450{ }^{\circ} \mathrm{C}$, according to Nelson and Summers (1983), to remove the organic part of total $\mathrm{C}$. The $\mathrm{OC}$ concentration was calculated by subtracting carbonaceous $\mathrm{C}$ from total $\mathrm{C}$, expressed as grams of OC per kilogram (hereafter $\mathrm{g} \mathrm{OC}$ per $\mathrm{kg}^{-1}$ ) dry matter dry matter. Homogenised samples were further analysed for $\delta^{13} \mathrm{C}$ values after carbonate removal in an isotope ratio mass spectrometer (DELTA Plus; Thermo Fisher Scientific, Waltham, MA, USA) coupled to an elemental analyser (FLASH EA 1122 NA 1500; Wigan, United Kingdom). Resulting $\delta^{13} \mathrm{C}$ values (per mille) were expressed relative to the international standard of Vienna Pee Dee Belemnite. The bulk densities for the soil samples were obtained with $250 \mathrm{~cm}^{3}$ sampling rings from each layer of the soil profile. For the sedimentary loess and Miocene sand samples, the bulk density of the deepest soil sample (94 and $100 \mathrm{~cm}$, respectively) was used. The bulk densities and densities without pore space of the intact Red Sandstone cores were determined on four subsamples (from 1.6, 3.6, 7, and $9 \mathrm{~m}$ depth) with a DryFlo pycnometer (GeoPyc 1360) and a gas pycnometer (AccuPyc 1330), respectively. Bulk densities for the missing depth increments were linearly interpolated. For radiocarbon $\left({ }^{14} \mathrm{C}\right)$ analysis, the sediment samples were first treated with $1 \% \mathrm{HCl}$ to remove inorganic $\mathrm{C}$, and then transferred into precombusted quartz ampoules containing copper oxide and silver wool. The ampoules were evacuated, flame sealed, and then combusted at $900{ }^{\circ} \mathrm{C}$, and the $\mathrm{CO}_{2}$ evolved was purified on a vacuum ring (Rethemeyer et al., 2019). The ${ }^{14} \mathrm{C}$ contents were measured with the MICADAS accelerator mass spectrometry (AMS) system at ETH Zurich, Switzerland. Where possible, one sedimentary sample per depth increment and site and one sample per soil layer was analysed. Due to the very low OC contents in some sediment samples, ${ }^{14} \mathrm{C}$ contents could only be determined for three samples from the Miocene sand (from 1.9, 4.9, and $7.9 \mathrm{~m}$ depth) and four from the Red Sandstone (1.9, 4.9, 7.9, and $9.9 \mathrm{~m}$ depth). For the loess, ${ }^{14} \mathrm{C}$ of bulk OC was measured in all depth intervals $(1.9-9.9 \mathrm{~m})$.

Total OC stocks (megagrams per hectare) were calculated according to Eq. (1), as follows:

$\mathrm{OC}$ stock $=\mathrm{OC} \cdot \mathrm{BD} \cdot(1-$ stone content $) \cdot \operatorname{depth} \cdot 0.1$,

where OC is the weight-based OC content, either in the fine soil $<2 \mathrm{~mm}$ fraction of the soil profiles or in the sediments (grams per kilogram), BD is the bulk density of the fine soil (grams per cubic centimetre), stone content is the volumebased proportion of stones (cubic centimetres per cubic centimetre), and depth is the thickness of the depth increment (centimetres). To be able to compare OC stocks and contributions from GOC, it was decided to set the borders between the topsoils and subsoils at $0.3 \mathrm{~m}$ and the transition from subsoils to the sediments at $1.5 \mathrm{~m}$. According to Richter and Markewitz (1995), this represents a common border for the transition from soil to sediment. The sediments were further subdivided into an upper and a lower part at a depth of $4 \mathrm{~m}$. 

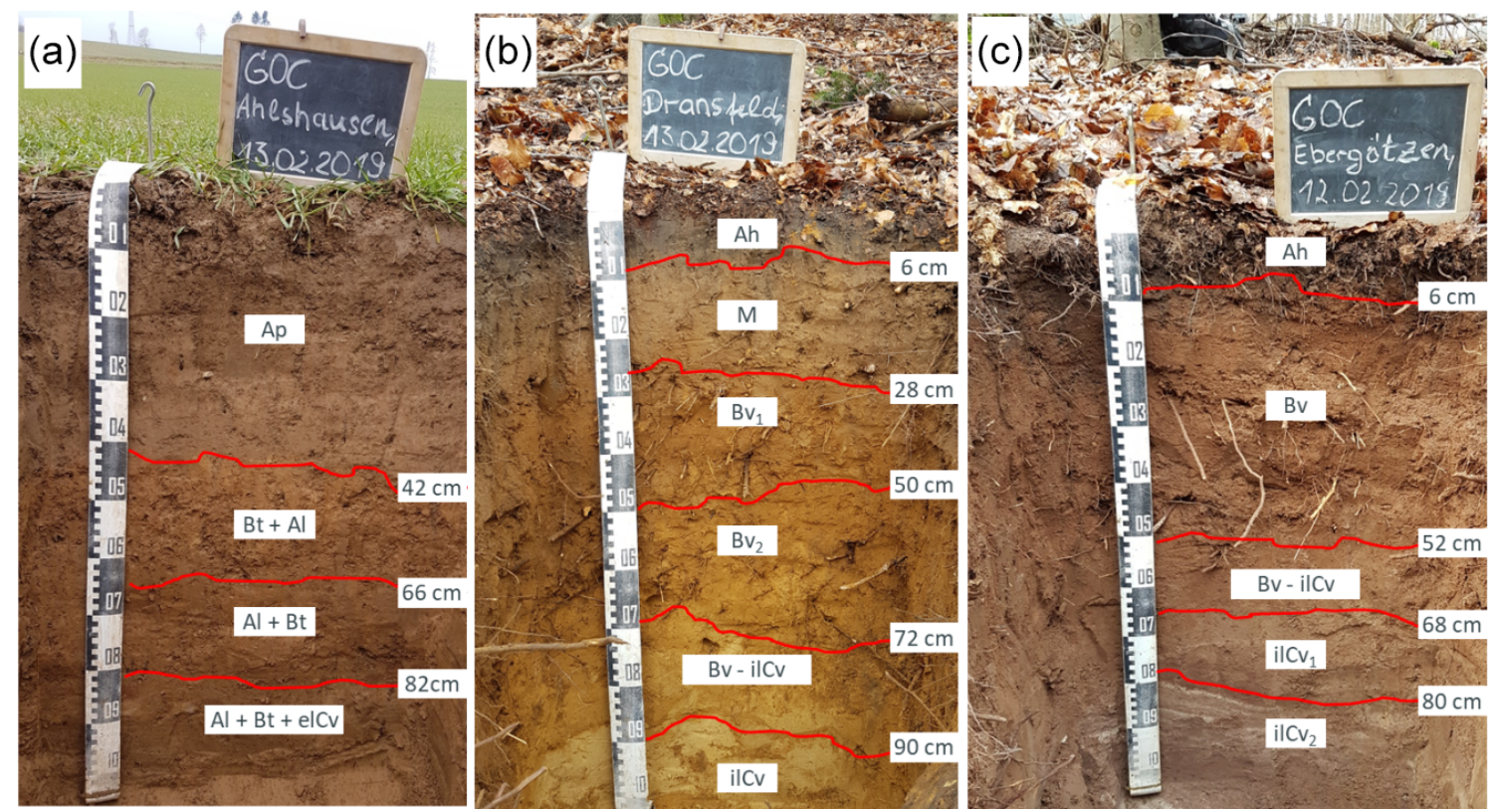

Figure 1. Respective soil profiles at the loess (a), Miocene sand (b), and Red Sandstone (c) sites. Soil classification was conducted using the German classification system for soil horizons (Eckelmann et al., 2006) and later transferred to the World Reference Base (WRB, 2006). Depth transitions to the starting sediment were $82 \mathrm{~cm}$ for loess $(\mathrm{Al}+\mathrm{Bt}+\mathrm{elCv}), 72 \mathrm{~cm}$ for Miocene sand $(\mathrm{Bv}-\mathrm{ilCv})$, and $68 \mathrm{~cm}$ for $\mathrm{Red}$ Sandstone $\left(\mathrm{ilCv}_{1}\right)$.

In a second step, the amount of GOC and biogenic OC in the sediments was calculated, considering GOC as one carbon pool free of ${ }^{14} \mathrm{C}$. For the sediments, the proportion of biogenic OC $\left(f_{\text {biogenic }}\right)$ of the total amount of OC was calculated in a two-pool model (Eq. 2) used by Cerri et al. (1985), as follows:

$f_{\text {biogenic }}(\%)=\frac{F_{\text {biogenic OC }}-F_{\mathrm{GOC}}}{F_{\text {sample }}-F_{\mathrm{GOC}}} \cdot 100$,

where $F$ represents the ${ }^{14} \mathrm{C}$ content in the fraction modern carbon $\left(\mathrm{F}^{14} \mathrm{C}\right)$ from a source compared with the ${ }^{14} \mathrm{C}$ content of an oxalic standard (Stuiver and Polach, 1977; Torn et al., 2009). The sources were the GOC fraction $\left(F_{\mathrm{GOC}}\right)$, the sample $\left(F_{\text {sample }}\right)$, and the biogenic OC fraction $\left(F_{\text {biogenic OC }}\right)$. Since the ${ }^{14} \mathrm{C}$ content of the GOC fraction can be set to zero, this equation could be simplified to the following:

$f_{\text {biogenic }}(\%)=\frac{F_{\text {biogenic OC }}}{F_{\text {sample }}} \cdot 100$.

For the biogenic $\mathrm{OC}$ in the sediments, an average ${ }^{14} \mathrm{C}$ age ranging from 1000-4000 years BP was assumed, based on published ${ }^{14} \mathrm{C}$ results of dissolved $\mathrm{OC}$ reaching greater depths (Artinger et al., 1996; Schiff et al., 1997). The ${ }^{14} \mathrm{C}$ contents in the sediment from 2 to $4 \mathrm{~m}$ depth of the loess led to ages $<3000$ years BP and were therefore even younger than at $74 \mathrm{~cm}$ depth (4413 years BP). Thus, they were treated like the soil part for the calculation below of a GOC fraction. Respective times were converted into ${ }^{14} \mathrm{C}$ contents
( $F_{\text {biogenic OC }}$, according to Torn et al. (2009), as follows:

$F_{\text {biogenic OC }}=e^{\left(\frac{t}{-8033}\right)}$,

where $t$ represents the ${ }^{14} \mathrm{C}$ age (1000 or 4000 years BP respectively), and 8033 represents the mean life of radiocarbon in years. The proportion of GOC in the sediments $\left(f_{\mathrm{GOC}}\right)$ is therefore the portion left (Eq. 5), as follows:

$f_{\mathrm{GOC}}=100 \%-f_{\text {biogenic }}$.

For the depth increments without measured ${ }^{14} \mathrm{C}$ ages (Table $\mathrm{S} 1$ ), the calculated amounts were linearly interpolated with measured ${ }^{14} \mathrm{C}$ ages from samples above and below. This was done by assuming a depth-dependent correlation and using the adjacent values. To calculate the amount of GOC in the soil profiles, the weight-based amount of GOC in the sediments was first calculated by multiplying its fraction $\left(f_{\mathrm{GOC}}\right)$ by the respective $\mathrm{OC}$ content (in $\mathrm{g} \mathrm{OC}$ per $\mathrm{kg}^{-1}$ dry mass).

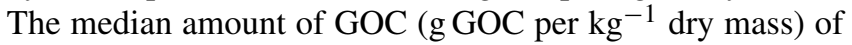
these sedimentary values was then taken and its proportion of soil OC content calculated ( $\mathrm{g} \mathrm{OC} \mathrm{per} \mathrm{kg}{ }^{-1}$ fine soil) in the soil profile. This was done for the proportion of GOC in the sediments calculated with a 1000- and a 4000-year-old biogenic OC fraction ( $F_{\text {biogenic OC }}$ in Eq. 3 ) to obtain a range of $\mathrm{GOC}$ contributions. It was assumed that the GOC fraction resisted degradation during soil formation. Therefore, this proportion represents the largest possible amount of GOC that could contribute to soil OC stocks. Based on this assumption, it was also possible to define the influence of GOC in 
the soil profile on the resulting ${ }^{14} \mathrm{C}$ ages. Since the calculated ${ }^{14} \mathrm{C}$ ages represent a mixture of the ${ }^{14} \mathrm{C}$ content from GOC and the biogenic fraction (Eq. 5), the GOC fraction has the same influence on the soil ${ }^{14} \mathrm{C}$ age as on bulk OC (according to Eq. 3). Reducing the age by this fraction would, therefore, represent an unbiased age of soil-derived OC.

\subsection{Incubation experiment}

To assess the potential stability of $\mathrm{OC}$ in the sediments against microbial decay, two laboratory incubation experiments were conducted at $20^{\circ} \mathrm{C}$ for 50 and $63 \mathrm{~d}$ respectively. This was done to reveal the potential degradation of OC from the sediments. A temperature of $20^{\circ} \mathrm{C}$ was chosen because only very low degradation rates were expected at lower temperatures. The first, $50 \mathrm{~d}$ experiment was conducted with intact Red Sandstone core samples, while the second experiment was performed after the Red Sandstone was crushed to pieces $<2 \mathrm{~mm}$ to simulate the process of weathering when the intact sediment or sedimentary rock becomes part of the (sub)soil. For the incubations, four subsamples of 1340$6890 \mathrm{~g}$ per sample from different depth intervals were used. The sample material was stored at room temperature until the start of the incubation experiment. A total of four samples were taken from each sediment and from each of four depth ranges for Miocene sand (1.2-2.8, 3.2-4.8, 6.1-7.8, and 8.2-9.9 m), Red Sandstone (2-3, 4-5.8, 7-8, and 8.4$9.8 \mathrm{~m})$ and loess $(1.4-2,2.7-3,4.8-6$, and $9.1-10 \mathrm{~m})$. Water content was adjusted to correspond to $40 \%$ of water-holding capacity based on the poured bulk density, determined by filling the loose material into a defined volume and measuring its weight. The material for the four repetitions was mixed in large plastic vats and water added before the respective four subsamples were transferred to incubation vessels. There were also four blank samples with no material. Based on preliminary tests and their calculated bulk density and porosity, the intact Red Sandstone samples were kept in a barrel with pure water for $14 \mathrm{~h}$ to reach a water content of nearly $40 \%$. Samples were placed in polycarbonate vessels with a volume of $7069 \mathrm{~cm}^{3}$ and made airtight. The lids contained two tube connectors so that the samples could be flushed with ambient air. After flushing, samples were set to a starting pressure of about $1300 \mathrm{mbar}$ and kept closed until the end of the incubation. A total of nine gas samples were taken in evacuated glass vials $(20 \mathrm{~mL}) 0,3,7,13$, $21,30,59$, and $63 \mathrm{~d}$ after the start of incubation. Samples were analysed for $\mathrm{CO}_{2}$ concentrations by gas chromatography (Agilent 7890A GC; Agilent Technologies, Santa Clara, CA, USA) to account for the amount of accumulated $\mathrm{CO}_{2}$. In total, three additional gas samples were taken 0,30 , and $63 \mathrm{~d}$ after the incubation started and analysed with an isotope ratio mass spectrometer (DELTA Plus XP; Thermo Fisher Scientific, Bremen, Germany) to account for the development of $\delta^{13} \mathrm{C}$ of $\mathrm{CO}_{2}$ during the respiration. The corresponding pressure was measured on each sampling date. When the over- pressure of a vessel was lost due to leakages, it was removed from the sampling because contamination with ambient air could no longer be ruled out. This happened for a third of all the samples.

The amount of respired $\mathrm{CO}_{2}-\mathrm{C}$ (milligrams of carbon dioxide carbon per day) was calculated using Eq. (6).

$\mathrm{CO}_{2}-\mathrm{C}=\frac{0.1 \cdot p \cdot x_{i} \cdot M \cdot V}{R \cdot T \cdot t}$,

where $p$ is the pressure (millibar), $x_{i}$ is the difference in $\mathrm{CO}_{2}$ concentration between the samplings (parts per million), $M$ is the molar mass of $\mathrm{C}$ (gram per mole), $V$ is the air volume of the sample (cubic metres), $R$ is the molar gas constant (joules per kilomole and Kelvin), $T$ is the incubation temperature (Kelvin), and $t$ is the elapsed time (days) between the sampling. Based on the $\delta^{13} \mathrm{C}$ values of $\mathrm{CO}_{2}$, the proportion of $\mathrm{CO}_{2}$ derived from carbonates was subtracted where necessary, according to Bertrand et al. (2007). This respiration rate was related to the OC content of the samples (called OCnormalised respiration) by being divided by the total amount of OC in grams in the sample.

Since we observed that an almost linear respiration behaviour was observed in both incubation experiments, a simple linear regression model was fitted to describe the mineralisation rate per time (mineralised OC $(\%)=k \cdot t)$.

\subsection{Statistics}

Statistical analyses were conducted using the statistical environment R (R Core Team, 2018) including the function "lm" to fit linear models and the package ggplot2 (Wickham, 2016) for graphical presentation. The models were tested for deviations from homoscedasticity, normality of residuals, and absence of collinearity. The tests revealed heteroscedasticity of the residuals, which can be explained by an increasing standard deviation with time. It subsequently became apparent that the residuals were not normally distributed since the dependent variable, representing the proportion of OC being mineralised, only allows values between 0 and 1 . Bearing this in mind, the results should be treated as an indicator of differences between the samples and a scale for the mineralisation of the OC pool. Therefore, calculations of standard errors and significance of the parameters were omitted since this would not produce reasonable results with the model used.

\section{Results}

\subsection{Relationship between sedimentary and subsoil organic carbon}

Using three laboratory replicates per sample and comparing them with the muffled samples, measurable OC contents were detected in all the sediments analysed. The mean relative standard deviation of the laboratory replicates was $9.5 \%$. 

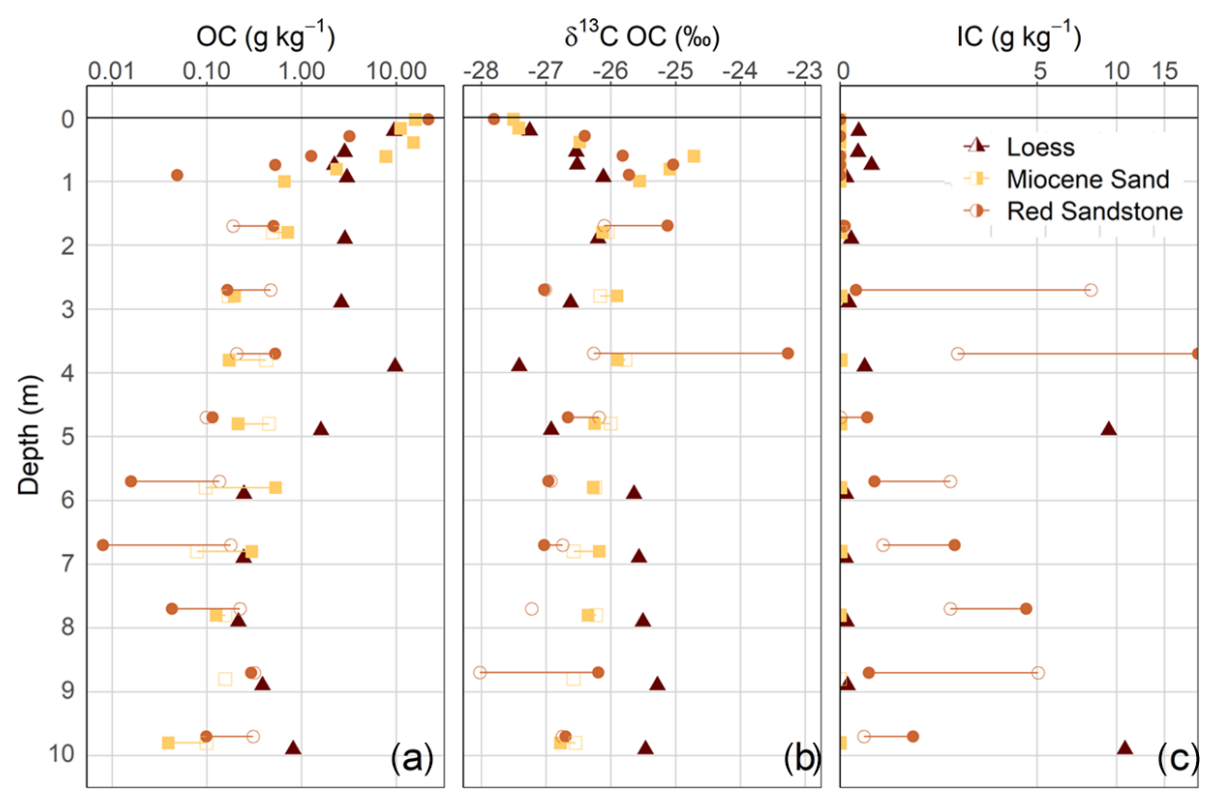

Figure 2. Depth distribution of different bulk properties of the soil profiles and deep drilling cores. Presented parameters include the logscale organic carbon (OC) and inorganic carbon (IC) content $(\mathbf{a}, \mathbf{c})$ and the $\delta^{13} \mathrm{C}$ values of the organic carbon (b) related to the amount of fine soil or dry mass, respectively. Filled and unfilled symbols represent the two different cores. For the loess, only one core could be analysed.

In terms of the detection limit, the sample with the lowest total $\mathrm{C}$ content (mean of $0.04 \mathrm{~g} \mathrm{C} \mathrm{kg}^{-1}$ soil) showed values between 0.00 and $0.01 \mathrm{~g} \mathrm{C} \mathrm{kg}^{-1}$ soil after the removal of $\mathrm{OC}$ at $450^{\circ} \mathrm{C}$. Thus, the range of 0.00 to $0.01 \mathrm{~g} \mathrm{C} \mathrm{kg}^{-1}$ soil was assumed to be the mean standard error from the measurement. Despite having the same material down to $10 \mathrm{~m}$ depth at each site, there were still some inhomogeneities that were visible and measurable. This was especially true for loess and Red Sandstone. The amount of OC in the sediments from 1 to $10 \mathrm{~m}$ depth was comparatively low in Miocene sand and Red Sandstone $\left(0.04-0.71 \mathrm{~g} \mathrm{~kg}^{-1}\right.$ and $0.01-0.53 \mathrm{~g} \mathrm{~kg}^{-1}$, respectively), while much higher OC contents of $0.21-9.71 \mathrm{~g} \mathrm{C} \mathrm{kg}^{-1}$ were found in loess (Fig. 2a). The median OC content of the sediments was within a range comparable to that of the respective deepest subsoil horizon. This deepest horizon was a Cv horizon (see Fig. 1) at $82 \mathrm{~cm}$ depth for loess, $90 \mathrm{~cm}$ depth for Miocene sand, and $80 \mathrm{~cm}$ depth for Red Sandstone. In detail, the median OC content in the sediments, compared with the respective $\mathrm{Cv}$ horizons, corresponded to $27 \%$ for loess, $29 \%$ for Miocene sand, and $39 \%$ for Red Sandstone. The loess OC contents were highly variable, highlighting the changing sedimentary conditions during the past glacial and interglacial periods (Jordan and Schwartau, 1993). At 4-5 m depth, the OC contents of loess were even higher $\left(9.7 \mathrm{~g} \mathrm{~kg}^{-1}\right)$ than in the subsoil $\left(3 \mathrm{~g} \mathrm{~kg}^{-1}\right)$. This was not an outlier because the high OC content could be visually confirmed by the very dark colour of the sample. In Miocene sand and Red Sandstone, no clear depth gradient of OC was found at 2-10 m depth (Fig. 2a). Even though the OC content in the sediments was low, the OC stocks could be very large. A comparison of OC stocks in topsoils $(0-0.3 \mathrm{~m})$, subsoils $(0.3-1.5 \mathrm{~m})$, and the sediments down to $10 \mathrm{~m}$ depth revealed quite high OC stocks in the sediments. For loess, OC in the sediment contributed up to $71 \%$ of the total OC amount, while it was $51 \%$ for Red Sandstone and $21 \%$ for Miocene sand (Table 1).

The distribution of the $\delta^{13} \mathrm{C}$ values of $\mathrm{OC}$ in the soil and sediment profiles showed an increase in $\delta^{13} \mathrm{C}$ with depth in the soil down to $1 \mathrm{~m}$ (Fig. 2b). In contrast, the $\delta^{13} \mathrm{C}$ values of OC in the sediments showed no clear trend with increasing depth, but they were all within the range of $\mathrm{C}_{3}$ plant material. A value above $-25 \%$ o for Red Sandstone at $4 \mathrm{~m}$ depth could be explained by the high values of inorganic carbon (IC) at this depth. It can be assumed that decarbonisation of this sample was not completely successful. Unexpectedly high amounts of IC were found in parts of Red Sandstone, indicating the presence of calcareous deposits in this terrestrial material (Fig. 2c). The loess also included some distinct calcareous layers at 5 and $10 \mathrm{~m}$ depth, while there were only small amounts of around $0.1 \mathrm{mg} \mathrm{IC} \mathrm{g}^{-1}$ soil at the other depths. This could be due to the fact that the investigated loess deposits belong to the Leine-Ilme Basin, a region with aeolian loamy loess that has been decalcified during weathering and soil genesis (Wagner, 2011), while the contents in the soil profile can be explained by liming. No IC was present in Miocene sand. 
Table 1. OC stocks and proportions for the three sites down to $10 \mathrm{~m}$ depth. Proportions of biogenic and geogenic OC were calculated based on the ${ }^{14} \mathrm{C}$ results and assumptions described in Sect. 2. Represented ranges are calculated based on the assumption of a 1000- or 4000-year-old biogenic OC fraction reaching the sediments.

\begin{tabular}{|c|c|c|c|c|c|c|c|c|}
\hline \multirow[t]{3}{*}{ Substrate } & \multirow[t]{3}{*}{ Layer } & \multirow{3}{*}{$\begin{array}{r}\text { Depth } \\
\text { (m) }\end{array}$} & \multicolumn{2}{|c|}{ TOC } & \multicolumn{2}{|c|}{ OC stocks $\left(\mathrm{Mg} \mathrm{ha}^{-1}\right)$} & \multicolumn{2}{|c|}{ Proportion of OC $(\%)^{\mathrm{b}}$} \\
\hline & & & $\left(\mathrm{Mg} \mathrm{ha}^{-1}\right)$ & $(\%)^{\mathrm{a}}$ & Geogenic & Biogenic & Geogenic & Biogenic \\
\hline & & & & & 4000 years & 1000 years & 4000 years & 1000 years \\
\hline \multirow[t]{4}{*}{ Loess } & Topsoil & $0.0-0.3$ & 40.6 & 11 & $1.1-1.2$ & $40-39$ & $3-3$ & $97-97$ \\
\hline & Subsoil & $0.3-1.5$ & 66.0 & 17 & $5.1-5.3$ & 61-61 & $8-8$ & $92-92$ \\
\hline & Upper sediment & $1.5-4.0$ & 218.6 & 57 & $10.6-11.0$ & 208-208 & $5-5$ & $95-95$ \\
\hline & Lower sediment & $4.0-10.0$ & 55.1 & 15 & $42.9-46.7$ & $8-12$ & $78-85$ & $15-22$ \\
\hline Red & Topsoil & $0.0-0.3$ & 22.2 & 30 & $0.6-0.7$ & $22-22$ & $3-3$ & 97-97 \\
\hline \multirow[t]{3}{*}{ Sandstone } & Subsoil & $0.3-1.5$ & 13.7 & 19 & $1.6-1.7$ & $12-12$ & $12-12$ & $88-88$ \\
\hline & Upper sediment & $1.5-4.0$ & 18.7 & 25 & $13.1-14.9$ & 4-6 & $70-80$ & $20-30$ \\
\hline & Lower sediment & $4.0-10.0$ & 19.3 & 26 & $14.1-15.7$ & $4-5$ & $73-82$ & $18-27$ \\
\hline Miocene & Topsoil & $0.0-0.3$ & 39.1 & 31 & $0.3-0.3$ & $39-39$ & $1-1$ & 99-99 \\
\hline \multirow[t]{3}{*}{ Sand } & Subsoil & $0.3-1.5$ & 60.8 & 48 & $1.3-1.6$ & $59-60$ & $2-3$ & 97-98 \\
\hline & Upper sediment & $1.5-4.0$ & 10.6 & 8 & $3.7-5.8$ & $5-7$ & $34-55$ & $45-66$ \\
\hline & Lower sediment & $4.0-10.0$ & 16.3 & 13 & $8.3-10.8$ & $6-8$ & $51-66$ & $34-49$ \\
\hline
\end{tabular}

a Percent of total OC stock from 0-10 m. ${ }^{\mathrm{b}}$ Percent of OC stock in the respective depth increment.

\subsection{Ages of organic carbon in soils and sediments and contributions from geogenic organic carbon}

The ages of OC in the loess soil profiles revealed a modern carbon signature (0 years BP) at $0.3 \mathrm{~m}$ depth, with a sharp increase up to $4413 \pm 51$ years BP at $0.7 \mathrm{~m}$ depth (Fig. 3a). For the Red Sandstone soil profile there was only an increase in the ages from a modern signature at $0.04 \mathrm{~m}$ to $532 \pm 41$ years BP at $0.3 \mathrm{~m}$ depth. The Miocene sand soil profile at $0.4 \mathrm{~m}$ depth showed an increase from $1277 \pm 41$ to $1771 \pm 44$ years BP at $0.6 \mathrm{~m}$ depth. Thus, OC of the subsoil (around $0.6 \mathrm{~m}$ depth) in loess was more than twice as old as in Miocene sand. In contrast, loess had a modern signature at $0.3 \mathrm{~m}$, while the soil developed in Red Sandstone showed an average age of $532 \pm 41$ years BP at $0.3 \mathrm{~m}$ depth.

The ages of $\mathrm{OC}$ in the sediments ranged from 2200-30730 years BP, with respective mean ages of $9077 \pm 3234$ years BP for Miocene sand, $13674 \pm 9632$ years BP for loess, and $14463 \pm 1992$ years BP for Red Sandstone. For all sediments, 11 out of 16 samples had a ${ }^{14} \mathrm{C}$ content that led to an ${ }^{14} \mathrm{C}$ age older than 11600 years $\mathrm{BP}$, which we assumed to be the time after the latest glacial period when soil development started (Litt et al., 2007). Therefore the sediments contained a mixture of geogenic (without ${ }^{14} \mathrm{C}$ ) and biogenic (with ${ }^{14} \mathrm{C}$ ) OC. Despite being the youngest sediment, loess partly revealed the highest apparent ${ }^{14} \mathrm{C}$ ages up to $30730 \pm 631$ years BP (Fig. 3a). The ages of OC in the sediment of Red Sandstone and Miocene sand ranged from $12940 \pm 132$ to $17390 \pm 206$ years BP and from $6750 \pm 86$ to $12770 \pm 151$ years BP respectively, revealing no depth trend with age in the deeper sediment. The calculated GOC fraction in the sediments was highest for Red Sandstone, ranging from $67 \%$ to $87 \%$, with a mean of $77 \%$ (Fig. 3b). For the three Miocene sand samples, the GOC fraction ranged from $29 \%$ to $77 \%$, with a mean of $53 \%$. Loess showed a sharp increase at a depth of $5 \mathrm{~m}$, where the GOC contribution rises to between $71 \%$ to $98 \%$ while it was only $5 \%$ to $19 \%$ at the 2 to $4 \mathrm{~m}$ depth.

The calculated weight-based content of GOC in the sediment revealed a comparatively uniform distribution for all the sediments with depth, except the extremely high contents of loess at $5 \mathrm{~m}$ depth (Fig. 3c). The investigated sediment depths revealed quite a narrow range of GOC contents, with $0.10 \pm 0.03 \mathrm{~g} \mathrm{~kg}^{-1}$ for Miocene sand, $0.17 \pm 0.12 \mathrm{~g} \mathrm{~kg}^{-1}$ for Red Sandstone, and $0.27 \pm 0.08 \mathrm{~g} \mathrm{~kg}^{-1}$ for loess.

\subsection{Biodegradability of sedimentary derived organic carbon}

The incubation experiment revealed a potential, but low, biodegradability of OC for all samples but without a clear depth gradient from 1 to $10 \mathrm{~m}$ (Fig. 4). To compare the effect of crushing on the respiration of Red Sandstone samples, the mineralisation rates from the first incubation experiment were compared with those of the second incubation experiment (Table 2). While Red Sandstone showed very low mineralisation when the samples were incubated as intact cores $\left(0.3-1.0 \mathrm{mg} \mathrm{CO}_{2}-\mathrm{Cg}^{-1} \mathrm{OC} \mathrm{yr}^{-1}\right)$, the mineralisation rate constants were up to 5 times higher when the samples were crushed (1.0-2.1 $\mathrm{mg} \mathrm{CO}_{2}-\mathrm{C} \mathrm{g}^{-1} \mathrm{OC} \mathrm{yr}^{-1}$ ). In a comparison of loess and Miocene sand, both re- 


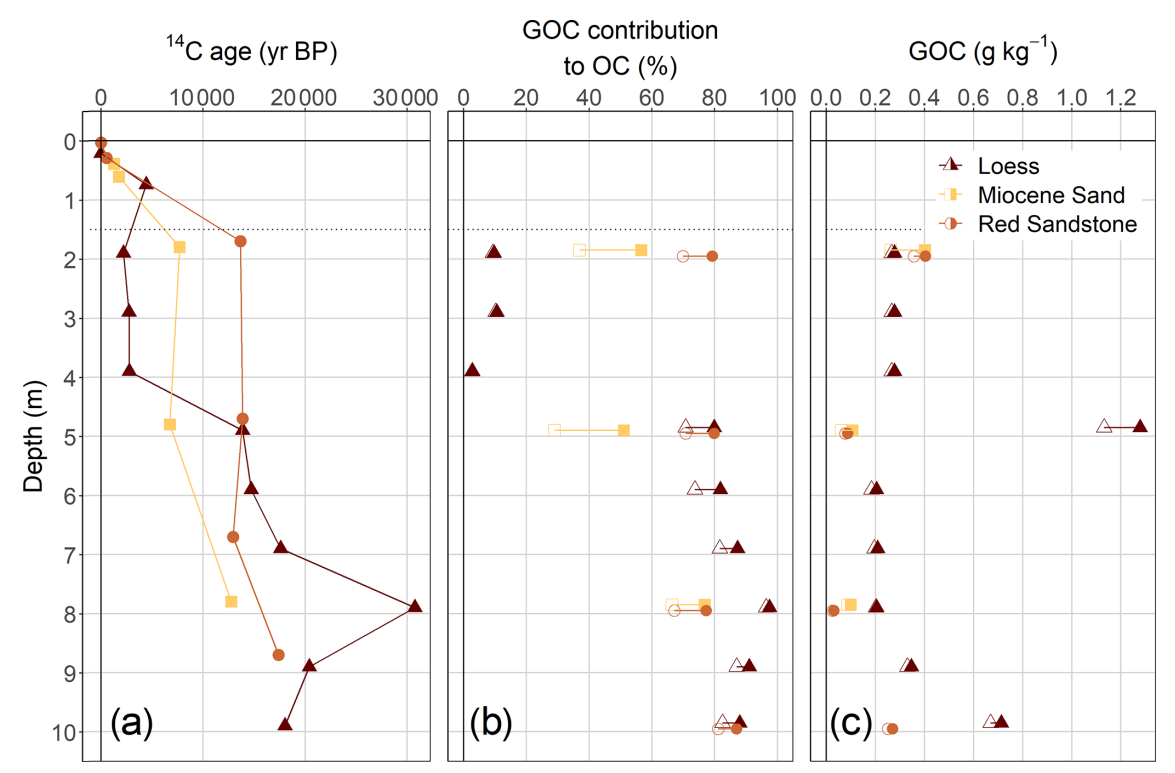

Figure 3. Depth distribution of apparent ${ }^{14} \mathrm{C}$ ages (in years BP) (a), GOC contribution to OC contents in the sediments, (b), and resulting weight-based amounts of GOC (c) in the sediments. The range in the contribution from GOC is due to the assumption of an average biogenic OC age of 4000 (empty shapes) and 1000 years (filled shapes).

vealed large differences between samples with the lowest (1.2 and $1.8 \mathrm{mg} \mathrm{CO}_{2}-\mathrm{C} \mathrm{g}^{-1} \mathrm{OC} \mathrm{yr}^{-1}$ ) and highest (34.2 and $12 \mathrm{mg} \mathrm{CO}_{2}-\mathrm{C} \mathrm{g}^{-1} \mathrm{OC} \mathrm{yr}^{-1}$ ) respiration rate constants. Interestingly, there was no depth gradient for the different substrates, but samples from 7 and $9 \mathrm{~m}$ depth of Miocene sand tended to have up to 6.8 times lower respiration rate constants than samples from the 2 and $4 \mathrm{~m}$ depth. There was also a very wide variation between samples from the same depth (see Fig. S1), as revealed by the high standard deviations. Assuming a constant mineralisation rate over time, the results of the incubation experiment would result in mean residence times of between 29 and 135 years for the loess, 83 and 556 years for the Miocene sand, and between 476 and 1000 years for the crushed Red Sandstone. Since the $\mathrm{CH}_{4}$ levels of the samples remained at a low level (Fig. S3), there were no indications of oxygen-limited conditions during the incubation.

\subsection{Possible contribution from geogenic organic carbon to soil organic carbon}

As bedrock weathers, it becomes part of the soil, and GOC also becomes soil OC. The potential amount of GOC in the subsoil was dependent on the sedimentary bedrock (Fig. 5). In the subsoil of Miocene sand, the proportion of GOC amounted to $2 \%-3 \%$, at the loess site it was $8 \%$, and at the Red Sandstone site it was $12 \%$ (Table 1). For the defined topsoils ( $0-30 \mathrm{~cm}$ depth), contributions of GOC to soil OC were smaller with $0.7 \%-0.9 \%$ for Miocene sand, $2.8 \%-2.9 \%$ for loess, and $2.8 \%-3.0 \%$ for Red Sandstone. The possible contribution of GOC to soil OC was also calculated under the assumption that the biogenic fraction had an unrealistically
Table 2. Comparison of mineralisation rate constants between the first (intact Red Sandstone samples) and second incubation experiments (crushed Red Sandstone samples) calculated using linear models.

\begin{tabular}{lrr}
\hline Substrate & $\begin{array}{r}\text { Depth } \\
(\mathrm{m})\end{array}$ & $\begin{array}{r}\text { Mineralisation rate constant } \\
\left(\mathrm{mg} \mathrm{CO}_{2}-\mathrm{C} \mathrm{g}^{-1} \mathrm{OC} \mathrm{yr}^{-1}\right)^{*}\end{array}$ \\
\hline Miocene sand & 2 & 12.0 \\
& 7 & 10.5 \\
& 9 & 1.8 \\
& 1.7 & 2.9 \\
\hline Loess & 2.9 & 7.4 \\
& 5.4 & 34.2 \\
& 9.6 & 10.2 \\
& 2.5 & 1.3 \\
\hline Uncrushed Red & 5 & 0.3 \\
Sandstone & 7.5 & 1.0 \\
& 9 & 0.4 \\
& 2.5 & 0.4 \\
\hline Crushed Red & 5 & 1.3 \\
Sandstone & 7.5 & 2.1 \\
& 9 & 2.0 \\
& & 1.0 \\
\hline The slope of the fitted linear model for respiration during the incubation & & \\
experiment. & &
\end{tabular}

high average age of 10000 years (Fig. S4). This resulted in the GOC fraction falling to 0 for Miocene sand. The geogenic fraction fell by $\sim 25 \%$ for loess and by $\sim 16 \%$ for Red Sandstone. 
The presence of ${ }^{14} \mathrm{C}$-free GOC in soil OC reduced the mean bulk soil $\mathrm{OC}{ }^{14} \mathrm{C}$ ages, depending on its proportion in soil OC content. Topsoils that developed in loess and Red Sandstone had a modern ${ }^{14} \mathrm{C}$ content of 1.029 and 1.035 $\mathrm{F}^{14} \mathrm{C}$, similar to the atmospheric ${ }^{14} \mathrm{C}$ content in 1950. Due to the large proportion of biogenic $\mathrm{OC}$, no influence of a geogenic fraction was detected in the topsoil of these sites. No ${ }^{14} \mathrm{C}$ data were available for the topsoil of Miocene sand. For all subsoils, the influence of GOC on bulk soil $\mathrm{OC}{ }^{14} \mathrm{C}$ content depended greatly on the depth and corresponding $\mathrm{OC}$ content. For loess, the possible influence on ${ }^{14} \mathrm{C}$ ages in the subsoils was quite high, with an average of $10 \%$ reduction in mean apparent ${ }^{14} \mathrm{C}$ ages in the subsoil. Thus, it would reduce the measured age of 4413 years BP in $74 \mathrm{~cm}$ depth by $532-555$ years BP. Geogenic OC potentially reduced the mean apparent radiocarbon age of 1277 years BP at $0.39 \mathrm{~m}$ depth in Miocene sand by about 7-9 years and the radiocarbon age of 1771 years BP at $0.61 \mathrm{~m}$ depth by $20-24$ years. These reductions are below the respective standard deviations of the measurement. Nevertheless, at $1 \mathrm{~m}$ depth a given possible proportion of $13.1 \%-16.3 \%$ would reduce an interpolated ${ }^{14} \mathrm{C}$ age of 3053 years BP by $399-497$ years. For Red Sandstone the influence of GOC on ${ }^{14} \mathrm{C}$ ages would be highest in the subsoil. At $74 \mathrm{~cm}$ depth it would increase an age of 1453 years BP by $451-490$ years BP. Due to the low amounts of soil OC at $90 \mathrm{~cm}$ depth at the Red Sandstone site, the weight-based median amount of GOC in the sediments was 4 times higher than the biogenic amount of soil OC.

\section{Discussion}

\subsection{Geogenic OC in the sediments}

It should be noted that these GOC calculations in sediments were based on the assumption of biogenic OC in the sediments not being older than 4000 years BP on average. The influence of a biogenic OC fraction derived from soils that developed before the latest glacial period was also excluded. Thus, it is possible that the biogenic OC fraction in the sediments is even older. Nevertheless, even with an assumed age of 10000 years for the biogenic OC fraction, the greatest possible contribution was $15.4 \%$ for loess (94 $\mathrm{cm}$ depth) and $21.5 \%$ for Red Sandstone ( $74 \mathrm{~cm}$ depth) (Fig. S4). Considering that modern $\mathrm{OC}$ entering the sediment has a quantitatively greater influence on measured ${ }^{14} \mathrm{C}$ ages than very old $\mathrm{OC}$, such high ages for the biogenic OC fraction seem unrealistic and would mean that almost no young OC enters the sediment. Given the high ${ }^{14} \mathrm{C}$ ages, it can therefore be assumed that some of the $\mathrm{OC}$ in the sediments comes from sedimentation as geogenic OC.

\subsubsection{Site-dependent contents of GOC}

Regarding the calculated contribution of GOC to OC in the sediments, the assumed range of biogenic ${ }^{14} \mathrm{C}$ ages from
1000-4000 years BP was within the typical range for ages of dissolved OC leaching from soils (Artinger et al., 1996; Jia et al., 2019). Nevertheless, the range of 1000-4000 years BP did not greatly influence the range of calculated sedimentary contribution from GOC, especially for loess $(\sim 6 \%$ difference) and Red Sandstone ( $\sim 9 \%$ difference). The calculated GOC contribution for Miocene sand was comparatively low (29\%-77\%) compared with the contribution for Red Sandstone and loess, especially at $5 \mathrm{~m}$ depth. Compared with the Red Sandstone, this could be due to deep biogenic carbon inputs, such as roots and root exudates from the trees (Angst et al., 2016; John et al., 2016; Kirfel et al., 2017; Tückmantel et al., 2017), since the loosely bedded Miocene sand allows for deep infiltration compared with the Red Sandstone site with its shallow bedrock as a root-restricting layer (Schneider and Don, 2019). Although it was not possible to define the exact rooting depth for Miocene sand, this depth probably does not exceed $4 \mathrm{~m}$, according to Schenk and Jackson (2005). Therefore, the increase in sedimentary contribution from 5 to $8 \mathrm{~m}$ depth of Miocene sand could be due to the decreasing influence of roots and root exudates at $8 \mathrm{~m}$ depth.

In loess, the low ${ }^{14} \mathrm{C}$ ages at $2-4 \mathrm{~m}$ depth (22002770 years BP), in contrast to a ${ }^{14} \mathrm{C}$ age of 4413 years BP at $0.74 \mathrm{~m}$ depth, were surprising. This might indicate past anthropogenic activities or an erosion-driven material movement that might have led to a mixing of the upper part of the profile. Furthermore, the modern ${ }^{14} \mathrm{C}$ signature at $21 \mathrm{~cm}$ depth could be due to the plough layer at the loess site mixing the upper $30 \mathrm{~cm}$. Nevertheless, at depths below $4 \mathrm{~m}$, the high ${ }^{14} \mathrm{C}$ ages of $\mathrm{OC}$ in the sediments indicated a large proportion of GOC. This could be due to different sedimentation periods, soil forming, and also soil burial processes (Chaopricha and Marin-Spiotta, 2014) that took place during the Pleistocene. These processes can lead to the presence of buried layers in loess with varying amounts of rather recalcitrant OC, as shown by Marin-Spiotta et al. (2014). For the investigated loess site, different sedimentation and soil-forming processes can be expected due to the presence of completely different material in the cores in terms of colour and measured OC contents. For example, the very dark loess at $4 \mathrm{~m}$ depth, with its high OC content, supports the assumption of sedimentation circumstances that favoured the accumulation and preservation of OC. This is in accordance with Jordan and Schwartau (1993), who investigated the same site and assigned the different layers to specific Pleistocene sedimentation periods.

In summary, the contribution of GOC to sedimentary OC was substrate dependent. A loosely bedded sediment like Miocene sand with extremely low concentrations of OC could be more prone to infiltration of biogenic OC and dilution of GOC. This resulted in contributions of biogenic OC to the sediments of about $50 \%$. In contrast, the loess site, with comparatively low infiltration rates, or the Red Sandstone site, with reduced possibilities for deep rooting, seemed 

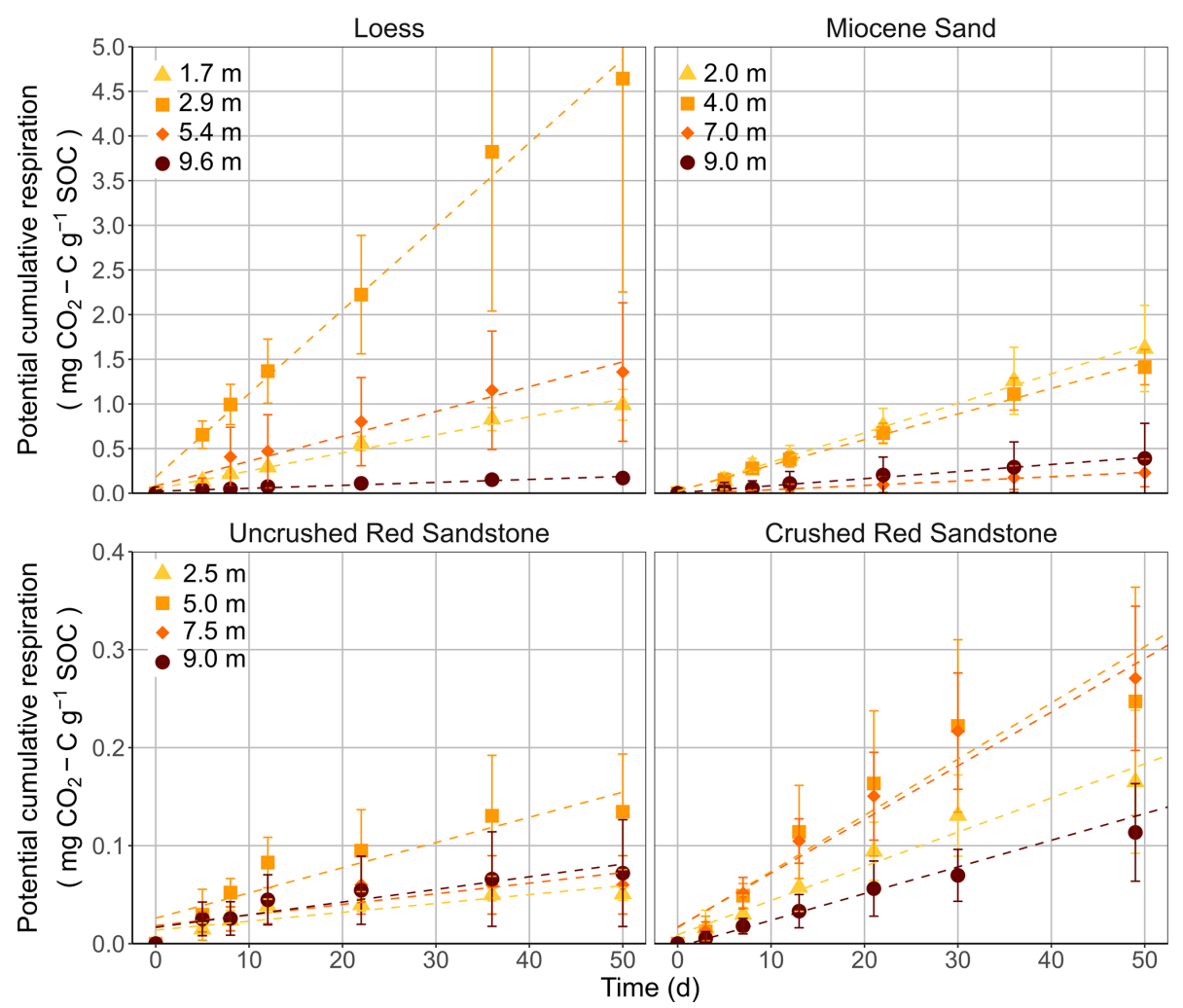

Figure 4. Potential degradability of sedimentary OC from three sites. Results represent cumulative respiration from loess and Miocene sand samples and both Red Sandstone incubation experiments with uncrushed and crushed samples, with respective standard deviations $(n=4)$. Dashed lines represent a fitted linear model to the respiration data.

to contain relatively constant contributions from GOC of around $80 \%$.

The GOC contribution within the sediments was not found to increase with soil depth. This is in contrast to the results of Frouz et al. (2011) which showed that different sediment types from a Miocene clay sediment had higher weightbased carbon contents at $150 \mathrm{~m}$, compared with $30 \mathrm{~m}$, depth. However, a comparison with the present study is difficult, since Frouz et al. (2011) did not distinguish between the geogenic and biogenic OC fractions, and OC contents were much higher (28-112 $\mathrm{g} \mathrm{kg}^{-1}$ dry mass compared to $0.008-$ $10 \mathrm{~g} \mathrm{~kg}^{-1}$ dry mass in our results). However, it also underlines the importance of different sedimentation processes for the amount and depth distribution of OC in sediments and sedimentary rocks.

\subsubsection{Geogenic OC in Miocene sand and Red Sandstone compared with other studies}

It is hard to compare the weight-based amounts of GOC in terrestrial sediments since most studies in this field rarely determine the amounts of OC in terrestrial sediments or presume that sandy sediments, for example, do not contain large amounts of OC (Artinger et al., 1996). Quite high amounts of OC have been found in the skeleton part of different soils on sandstones with $0.61-1.97 \mathrm{tha}^{-1}$ (Corti et al., 2002). Nevertheless, they mentioned the possible strong influence of organic substances from the soil solution without quantifying it and did not directly investigate OC in the sediments. Additionally, Copard et al. (2007) assumed an OC amount of $2.4 \mathrm{~g} \mathrm{~kg}^{-1}$ from an unknown source for all sandy sediments in a global storage modelling approach for the first metre of sediments. This would fit with the amounts of around 1 and $5 \mathrm{mg} \mathrm{OC}^{-1}$ found by Krumholz et al. (1997) for Dakota sandstone layers at $>180 \mathrm{~m}$ depth but is much greater than the median GOC amount in Red Sandstone $\left(0.2 \mathrm{~g} \mathrm{~kg}^{-1}\right)$ and Miocene sand $\left(0.1 \mathrm{~g} \mathrm{~kg}^{-1}\right)$ in the present study.

\subsubsection{Geogenic OC in loess compared with other studies}

Loess deposits are relatively well investigated because they provide a record of palaeoenvironmental conditions (Hatté et al., 1998; Head et al., 1989; Murton et al., 2015; Wang et al., 1996). The median amount of $0.27 \mathrm{~g} \mathrm{~kg}^{-1}$ from the present study was low compared with studies by Hatté et al. (1998), Wang et al. (1996), and Strauss et al. (2012). Hatté et al. (1998) investigated $20 \mathrm{~m}$ deep loess deposits in the Rhine valley and found OC contents between $1.0-8.6 \mathrm{~g} \mathrm{~kg}^{-1}$, Wang et al. (1996) investigated $12 \mathrm{~m}$ deep loess deposits 

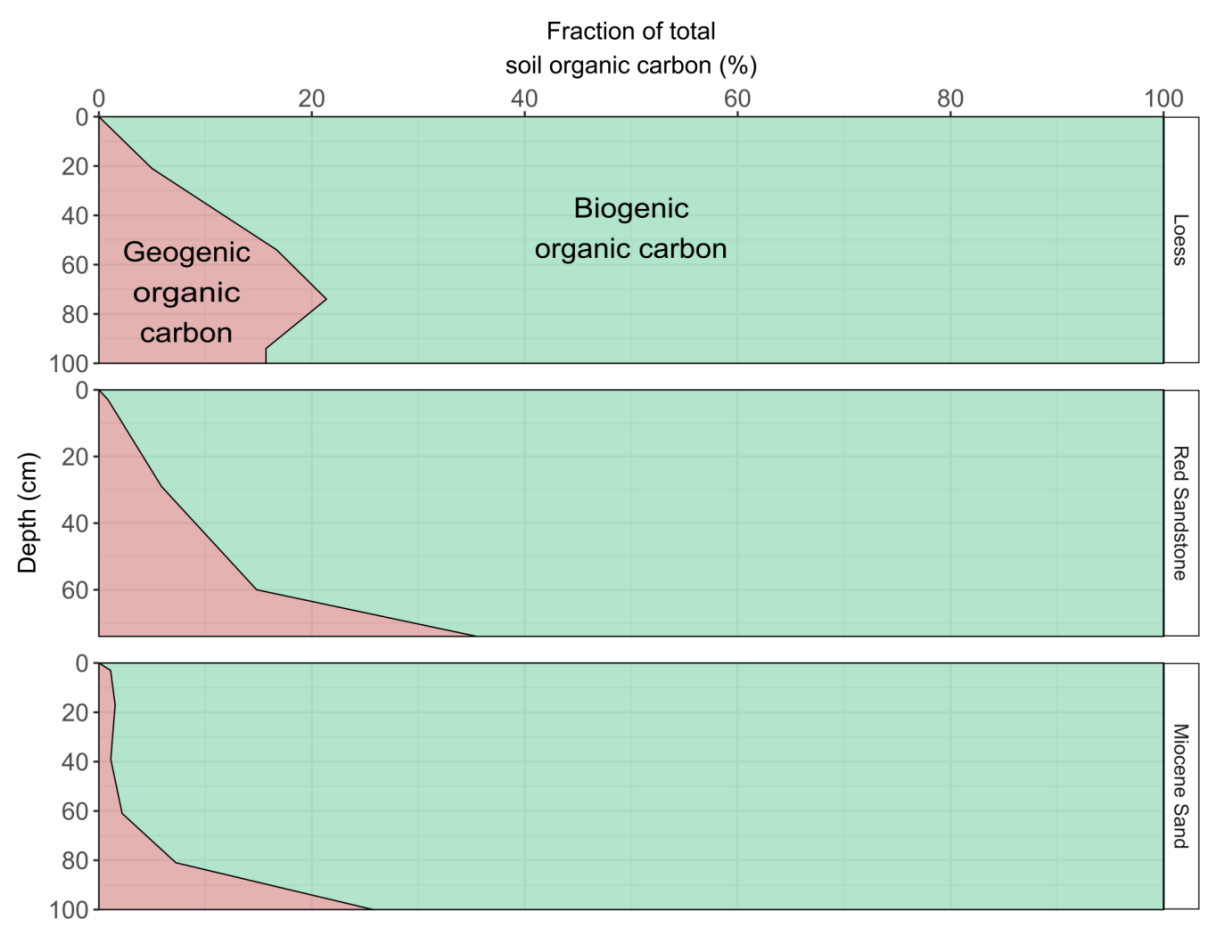

Figure 5. Largest possible contribution of GOC to OC (red area) in relation to bulk OC content, taking into account the median GOC contents of the sediments for the respective horizontal weight-based OC contents. The contribution of GOC is the mean amount based on the assumption of an average biogenic OC age of between 4000 and 1000 years.

in China and found OC contents of $31.2 \pm 30.5 \mathrm{~g} \mathrm{~kg}^{-1}$, and Strauss et al. (2012) found OC contents of $15 \pm 14 \mathrm{~g} \mathrm{~kg}^{-1}$ in Yedoma loess deposits in Siberia. This shows that the deposits from the site in the present study stored comparatively low GOC contents, although most of the above-mentioned studies do not distinguish between a biogenic and geogenic OC pool. Nevertheless, as also shown in the present study, loess had a high OC content compared with other sediments. This was in line with highest OC contents in subsoils at the loess site and may indicate the importance and contribution of bedrock OC to subsoil OC.

\subsection{Is sedimentary derived organic carbon biodegradable?}

The incubation experiment revealed a mineralisation of OC within the sediments, with values between $0.1 \%$ and $3.4 \%$ of total OC being mineralised after 1 year, assuming a constant mineralisation rate. The incubation temperature of $20^{\circ} \mathrm{C}$ should, therefore, be considered to be above the typical mean temperatures in the subsoils. For subsoils with comparable climatic conditions, Wordell-Dietrich et al. (2020) found temperatures at $150 \mathrm{~cm}$ depth ranging from 4 to $14.4^{\circ} \mathrm{C}$ over a 2-year period. Assuming a $Q_{10}$ value of around two for the assumable difference (Hamdi et al., 2013), the respiration rate at typical subsoil temperatures would be roughly half that. A direct mineralisation of OC from sediments is in agreement with several studies investigating the di- rect mineralisation from outcrops (Copard et al., 2007; Horan et al., 2017; Petsch et al., 2000; Soulet et al., 2018; Seifert et al., 2011). The difference, when compared to the present study, is that those studies observed this mineralisation when the sediments were directly exposed to the surface and/or were part of a very rapidly eroding area. Thus, GOC from the sediments is already in touch with the atmosphere and inputs of recent vegetation. However, Frouz et al. (2011) conducted an incubation experiment with sedimentary samples from OC-rich Miocene clay sediments and found quite high respiration rate constants, with values between 3.5-12.3 $\mathrm{mg} \mathrm{CO}_{2}-\mathrm{C} \mathrm{g}^{-1} \mathrm{OC} \mathrm{yr}^{-1}$ during a $91 \mathrm{~d}$ incubation experiment. They attribute this to the prevailing presence of aliphatic compounds in their samples being decomposed. Kieft and Rosacker (1991) also found high respiration rates of sedimentary samples, with values between $0.9-$ $9.5 \mathrm{mg} \mathrm{CO}_{2}-\mathrm{C} \mathrm{g}^{-1} \mathrm{OC} \mathrm{yr}^{-1}$, which they primarily attribute to the physiological status of the soil microbial community expressed as adenylate energy charge. Those results are in fairly good agreement with the respiration rate constants observed in the present study (1-34.2 $\left.\mathrm{mg} \mathrm{CO}_{2}-\mathrm{Cg}^{-1} \mathrm{OC} \mathrm{yr}^{-1}\right)$. Meanwhile, compared with the subsoil incubation experiments, the mineralisation found in the present incubation experiment was quite low. For example, in subsoil incubation experiments at $20^{\circ} \mathrm{C}$, Wordell-Dietrich et al. (2017) found that between 5 and $9.5 \mathrm{mg} \mathrm{CO}_{2}-\mathrm{Cg}^{-1} \mathrm{OC}$ of OC are mineralised after incubation for $63 \mathrm{~d}$, Wang et al. (2013) report 
values between 5 and $15 \mathrm{mg} \mathrm{CO} 2-\mathrm{Cg}^{-1}$ OC after $28 \mathrm{~d}$, and Soucemarianadin et al. (2018) report values between 10 and $12.5 \mathrm{mg} \mathrm{CO}_{2}-\mathrm{C} \mathrm{g}^{-1} \mathrm{OC}$ after $70 \mathrm{~d}$. The difference between the respiration rates observed in the present incubation experiment and the results from sedimentary and subsoil incubation experiments could be due to different microbial communities, OC quality, and the physical connection between OC and potential decomposers. As shown in a meta-analysis by Colman and Schimel (2013), different microbial compositions, their abundance, and the quality of OC, strongly affects respiration rates. This might also be indicative of extreme differences in respiration rates even within the same substrate and sample.

The results of the present study indicated that there was a considerable portion of biogenic OC in the sediments. The observed mineralisation could, therefore, be due primarily to the consumption of this biogenic OC part. Furthermore, the low mineralisation rate of Red Sandstone during the incubation as intact cores (Fig. S1) promoted the stability of GOC when it was part of the sediments. This might be due to the low accessibility of OC in the sediments for microorganisms and the low availability of water due to a preferential flow through the sandstone (Swanson et al., 2006).

Altogether, the low mineralisation rates of the $\mathrm{OC}$ in the sediments might be caused by a lack of fresh substrates and/or microorganisms that could enhance the degradation of OC (Fontaine et al., 2007). Seifert et al. (2011) have shown that microorganisms are able to degrade sedimentary OC after the addition of glucose in black slate outcrops. Nevertheless, mineralisation of OC could only be observed with the addition of water, which indicates the widely recognised assumption of the presence of an active microbial community in the sediments (Bomberg et al., 2017; Joergensen and Wichern, 2018; Magnabosco et al., 2018). Since fresh substrates were not added during the incubation, respiration rates could be even higher if a fresh substrate-induced priming effect occurs. Furthermore, the inherent and active microbial communities in the sediments might have assimilated ${ }^{14} \mathrm{C}$-free GOC into their biomass, as shown by Schwab et al. (2019). Thus, part of the labile OC pool in the sediments might also be derived from metabolised ${ }^{14} \mathrm{C}$-free microbial biomass.

The incubation experiment was unable to answer the question of whether GOC is mineralised when it becomes part of the (sub-)soil. Assuming that a large part of the biogenic OC in the sediments was mineralised during the incubation experiment, geogenic OC could still be preserved during soil formation, especially in the subsoils. This is in accordance with the indirect approach taken by Graz et al. (2010) to determine the mineralisation of sedimentary OC when it becomes part of the subsoil. They stated that $30 \%$ of GOC resists degradation when it becomes part of the soil due to the results of a quantitative palynofacies analysis of bedrock and soil samples. Hemingway et al. (2018) found that sedimentary OC directly exposed to the surface in a rapidly eroding tropical mountain area exhibits considerable mineralisation down to $1 \mathrm{~m}$ below the surface, also leading to around $30 \%$ of GOC remaining in the soil. Based on ${ }^{14} \mathrm{C}$ measurements, they found out that, on average, $67 \pm 11 \%$ of the OC fraction in the sediments could be lost during soil formation, but no distinction was made between biogenic and geogenic OC fractions. This indicates that a microbial mineralisation of bedrock OC takes place but may be partly restricted to biogenic OC.

Regarding the depth distribution of GOC in the sediments, the amount of GOC (in grams per kilogram) did not increase with depth, but there were clear differences. This reflects the sedimentation history with different initial amounts of OC and degradation during sedimentation, which is particularly evident in the high amounts of GOC at $5 \mathrm{~m}$ depth in loess. However, the contents of GOC, especially in Red Sandstone and Miocene sand, were within the same range for the whole depth. This might indicate that degradation of GOC is not depth dependent within the sediments. If there were a stronger degradation of GOC with decreasing depth, a decreasing amount of GOC could be expected due to the input of water, microorganisms, and fresh nutrients from above. Furthermore, there was a relatively constant contribution of biogenic OC within the sediments, meaning that, if biogenic OC enters the sediments with possibly degrading microorganisms, this biogenic $\mathrm{OC}$ might also be largely mineralised. A study by Heitkötter et al. (2018) demonstrates effectively that the degradation of $\mathrm{OC}$ in subsoils is primarily limited to small hot spot areas. Also, in sediments, Krumholz et al. (1997) show that microbial communities can particularly be found in spatially discrete areas. Nevertheless, Heitkötter et al. (2018) also show that microorganisms outside the hot spots can be activated when substrate is supplied. Thus the bioavailability of GOC might be very site dependent since root channels as microbial hot spots, for example, are less abundant and stable in sandy soils (Schneider and Don, 2019). With regard to the sites investigated here, the solid Red Sandstone might only obtain water in preferential flow paths (Swanson, 2006) leading to a comparatively stable OC pool in the sediment. Meanwhile, for weathered, poorly structured sandy soils, prevalent matrix flow conditions can be assumed (Flury et al., 1994). Thus, the bulk GOC might be supplied with fresh substrates and water from above more often than for the well-structured loess soil with more frequent and stable preferential flow paths (Schneider and Don, 2019). This might lead to a lower accessibility and, therefore, slower turnover rates of OC (Dungait et al., 2012).

The conclusion can be drawn that GOC can and will be degraded when it becomes part of the subsoil but probably to a comparatively limited extent. 


\subsection{How much does GOC contributes to soil organic carbon?}

The contribution of GOC to soil OC stocks in this study was driven by the amount of OC in the soil, the amount of GOC in the respective sediment and also the turnover of GOC when it becomes part of the soil. Our results revealed that, despite differing between sediments, GOC content varied in quite a narrow range between 0.1 and $0.3 \mathrm{~g} \mathrm{~kg}^{-1}$. The contribution of GOC to topsoil OC was negligible. Assuming no degradation of GOC, the greatest possible contributions to total subsoil OC were found for Red Sandstone $(\sim 30 \%)$ and the lowest for Miocene sand $(0.6 \%)$. This was due to the range of OC content in the subsoils $\left(0.53-15.21 \mathrm{~g} \mathrm{~kg}^{-1}\right)$. When soil OC contents were low, the possible contributions from GOC were high and vice versa. For the investigated soils, the OC contents of $3 \mathrm{~g} \mathrm{~kg}^{-1}$ soil allowed for possible GOC contributions of between $5 \%$ and $10 \%$. For OC contents around $1 \mathrm{~g} \mathrm{~kg}^{-1}$ soil, a GOC contribution of between $10 \%$ and $20 \%$ seemed possible. Thus, greater contributions were made by GOC-rich sediments such as loess, while smaller contributions were from sandy sediments. In comparison, van der Voort et al. (2019) estimated the contribution of GOC in a soil derived from glacial deposits (flysch) at between 80 and $100 \mathrm{~cm}$ depth to be around $40 \%$. For a soil developed from a poorly consolidated sedimentary rock (calcareous and shaly moraine), they calculate the contribution of GOC to range from $20 \%$ at $145 \mathrm{~cm}$ depth to $80 \%$ at $310 \mathrm{~cm}$ depth. An attempt has also been made to fractionate subsoils to extract the most stable OC that may be derived from GOC. Paul et al. (2001) investigated a soil developed on loess over till with $30 \%$ of subsoil OC as a non-hydrolysable fraction showing ${ }^{a}{ }^{14} \mathrm{C}$ age of 13000 years BP. They also concluded that this high ${ }^{14} \mathrm{C}$ age can partly be explained by a GOC fraction. These results indicate that deposits from the past glacial periods, such as flysch or till in particular, have much greater potential for OC contributions from GOC, possibly due to the higher amounts of GOC in their sediments. Since only terrestrial sediments were investigated in the present study, it should be noted that marine sediments or shales also contain much higher amounts of OC of up to $250 \mathrm{~g} \mathrm{~kg}^{-1}$ (Hemingway et al., 2018; Petsch et al., 2000). Thus, the amount of GOC they contain and their possible contribution to subsoil OC stocks might, therefore, be much higher.

Nevertheless, the ${ }^{14} \mathrm{C}$ ages of $\mathrm{OC}$ in the subsoil can be high in soils derived from igneous parent materials without GOC (Rumpel and Kögel-Knabner, 2002), although even crystalline bedrock contains microbial communities (Purkamo et al., 2020). Furthermore, on a global scale, the ${ }^{14} \mathrm{C}$ ages of soil OC are primarily driven by climatic conditions, clay content, and age of the soil (Mathieu et al., 2015). However, for terrestrial sediments with comparatively low amounts of GOC that started their soil development after the latest glacial period, a scale of possible contributions could be obtained when the amount of OC is known. Thus, on a global scale, the high
${ }^{14} \mathrm{C}$ age of subsoils is not driven just by the GOC fraction, but the presence of GOC may greatly influence subsoil ${ }^{14} \mathrm{C}$.

\section{Conclusions}

In this study, the amount of GOC in sediments and in the soil was analysed by radiocarbon dating. The aim was to find out if GOC from different terrestrial sediments can have an influence on soil OC stocks. This approach of estimating the GOC contribution to soil OC showed that common and abundant terrestrial sediments with low amounts of sedimentary OC can make a considerable contribution to soil OC stocks. One fraction of $\mathrm{OC}$ in the sediments is of geogenic origin and could, therefore, influence measured ${ }^{14} \mathrm{C}$ ages in soil, particularly in subsoils. Subsoils are known for their high ${ }^{14} \mathrm{C}$ ages and slow turnover rates and slow reaction to changing environmental condition. These subsoil OC properties may partly be derived from the GOC in the subsoil. The sediments at the investigated sites contained $\mathrm{OC}$ in a range of $0.1-0.3 \mathrm{~g} \mathrm{~kg}^{-1}$. These amounts allowed for contributions from GOC of between $10 \%$ and $30 \%$ in subsoils, defined here as soil horizons ranging from 0.3 to $1.5 \mathrm{~m}$ depth. Incubation of sediments indicated that this geogenic contribution presents a quite stable OC pool, especially for subsoils.

Data availability. The data will be made available on request.

Supplement. The supplement related to this article is available online at: https://doi.org/10.5194/soil-7-347-2021-supplement.

Author contributions. AD conceived of and designed the study. FK performed the sampling and analysis and wrote the first draft. All the authors (FK, FN, SWM, MH, JR, and AD) contributed to generating and reviewing the subsequent versions of the paper.

Competing interests. The authors declare that they have no conflict of interest.

Disclaimer. Publisher's note: Copernicus Publications remains neutral with regard to jurisdictional claims in published maps and institutional affiliations.

Acknowledgements. This study was funded by the Deutsche Forschungsgemeinschaft (DFG; grant no. DO1734/4-2) within the framework of the research unit SUBSOM (grant no. FOR1806) "The Forgotten Part of Carbon Cycling: Organic Matter Storage and Turnover in Subsoils". We would like to thank Frank Hegewald and the student assistants, for their support in the field and in the laboratory, Jens Dyckmanns and Lars Szwec, from the Centre for Stable Isotope Research and Analysis at the University of Göttingen for the 
${ }^{13} \mathrm{CO}_{2}$ measurements, Reiner Dohrmann, from the Federal Institute for Geosciences and Natural Resources for density measurements of sedimentary rocks, and Roland Prietz, for his excellent soil classification assistance. We would also like to thank the AK laboratory team for their support.

Financial support. This research has been supported by the Deutsche Forschungsgemeinschaft (DFG; grant no. DO1734/42) within the framework of the research unit SUBSOM (grant no. FOR1806).

Review statement. This paper was edited by Cornelia Rumpel and reviewed by Jeroen Zethof and two anonymous referees.

\section{References}

Amiotte Suchet, P., Probst, J. L., and Ludwig, W.: Worldwide distribution of continental rock lithology: Implications for the atmospheric/soil $\mathrm{CO}_{2}$ uptake by continental weathering and alkalinity river transport to the oceans, Global Biogeochem. Cy., 17, 1038, https://doi.org/10.1029/2002GB001891, 2003.

Angst, G., John, S., Mueller, C. W., Kogel-Knabner, I., and Rethemeyer, J.: Tracing the sources and spatial distribution of organic carbon in subsoils using a multi-biomarker approach, Sci. Rep., 6, 1-12, 2016.

Artinger, R., Buckau, G., Kim, J., Geyer, S., and Wolf, M.: Influence of sedimentary organic matter on dissolved fulvic acids in groundwater, Significance for groundwater dating with ${ }^{14} \mathrm{C}$ in dissolved organic matter, International Atomic Energy Agency (IAEA), 57-72, 1996.

Batjes, N. H.: Total carbon and nitrogen in the soils of the world, Eur. J. Soil Sci., 65, 10-21, 2014.

Bertrand, I., Delfosse, O., and Mary, B.: Carbon and nitrogen mineralization in acidic, limed and calcareous agricultural soils: Apparent and actual effects, Soil Biol. Biochem., 39, 276-288, 2007.

Bomberg, M., Raulio, M., Jylha, S., Mueller, C. W., Hoschen, C., Rajala, P., Purkamo, L., Kietavainen, R., Ahonen, L., and Itavaara, $\mathrm{M}$.: $\mathrm{CO}_{2}$ and carbonate as substrate for the activation of the microbial community in $180 \mathrm{~m}$ deep bedrock fracture fluid of Outokumpu Deep Drill Hole, Finland, AIMS Microbiol., 3, 846-871, 2017.

Cerri, C., Feller, C., Balesdent, J., Victoria, R., and Plenecassagne, A.: Particle-size fractionation and stable carbon isotope distribution applied to the study of soil organic-matter dynamics, Comptes Rendus De L Academie Des Sciences Serie Ii, 300, 423-428, 1985.

Chaopricha, N. T. and Marin-Spiotta, E.: Soil burial contributes to deep soil organic carbon storage, Soil Biol. Biochem., 69, 251264, 2014.

Colman, B. P. and Schimel, J. P.: Drivers of microbial respiration and net $\mathrm{N}$ mineralization at the continental scale, Soil Biol. Biochem., 60, 65-76, 2013.

Copard, Y., Amiotte-Suchet, P., and Di-Giovanni, C.: Storage and release of fossil organic carbon related to weathering of sedimentary rocks, Earth Planet. Sc. Lett., 258, 345-357, 2007.
Corti, G., Ugolini, F. C., Agnelli, A., Certini, G., Cuniglio, R., Berna, F., and Sanjurjo, M. J. F.: The soil skeleton, a forgotten pool of carbon and nitrogen in soil, Eur. J. Soil Sci., 53, 283298, 2002.

Crow, S. E., Lajtha, K., Filley, T. R., Swanston, C. W., Bowden, R. D., and Caldwell, B. A.: Sources of plant-derived carbon and stability of organic matter in soil: implications for global change, Global Change Biol., 15, 2003-2019, 2009.

Eckelmann, W., Sponagel, H., Grottenthaler, W., Hartmann, K.-J., Hartwich, R., Janetzko, P., Joisten, H., Kühn, D., Sabel, K.-J., and Traidl, R.: Bodenkundliche Kartieranleitung, KA5, Bundesanstalt für Geowissenschaften und Rohstoffe, Hannover, Germany, 438 pp., 2006.

Fontaine, S., Barot, S., Barre, P., Bdioui, N., Mary, B., and Rumpel, C.: Stability of organic carbon in deep soil layers controlled by fresh carbon supply, Nature, 450, 277-280, 2007.

Frouz, J., Cajthaml, T., Kribek, B., Schaeffer, P., Bartuska, M., Galertova, R., Rojik, P., and Kristufek, V.: Deep, subsurface microflora after excavation respiration and biomass and its potential role in degradation of fossil organic matter, Folia Microbiol., 56, 389-396, 2011.

Graz, Y., Di-Giovanni, C., Copard, Y., Laggoun-Defarge, F., Boussafir, M., Lallier-Verges, E., Baillif, P., Perdereau, L., and Simonneau, A.: Quantitative palynofacies analysis as a new tool to study transfers of fossil organic matter in recent terrestrial environments, Int. J. Coal. Geol., 84, 49-62, 2010.

Hatté, C., Fontugne, M., Rousseau, D.-D., Antoine, P., Zoller, L., Laborde, N. T. R., and Bentaleb, I.: $\delta^{13} \mathrm{C}$ variations of loess organic matter as a record of the vegetation response to climatic changes during the Weichselian, Geology, 26, 583-586, 1998.

Hamdi, S., Moyano, F., Sall, S., Bernoux, M., and Chevallier, T.: Synthesis analysis of the temperature sensitivity of soil respiration from laboratory studies in relation to incubation methods and soil conditions, Soil Biol. Biochem., 58, 115-126, 2013.

Head, M., Zhou, W., and Zhou, M.: Evaluation of ${ }^{14} \mathrm{C}$ ages of organic fractions of paleosols from loess-paleosol sequences near Xian, China, Radiocarbon, 31, 680-695, 1989.

Hemingway, J. D., Hilton, R. G., Hovius, N., Eglinton, T. I., Haghipour, N., Wacker, L., Chen, M.-C. and Galy, V. V.: Microbial oxidation of lithospheric organic carbon in rapidly eroding tropical mountain soils, Science, 360, 209-212, 2018.

Horan, K., Hilton, R. G., Selby, D., Ottley, C. J., Gröcke, D. R., Hicks, M., and Burton, K. W.: Mountain glaciation drives rapid oxidation of rock-bound organic carbon, Sci. Adv., 3, e1701107, https://doi.org/10.1126/sciadv.1701107, 2017.

Jia, J., Feng, X., Pannatier, E. G., Wacker, L., McIntyre, C., van der Voort, T., Montlucon, D., and Eglinton, T.: ${ }^{14} \mathrm{C}$ characteristics of dissolved lignin along a forest soil profile, Soil Biol. Biochem., 135, 407-410, 2019.

Joergensen, R. G. and Wichern, F.: Alive and kicking: Why dormant soil microorganisms matter, Soil Biol. Biochem., 116, 419-430, 2018.

John, S., Angst, G., Kirfel, K., Preusser, S., Mueller, C. W., Leuschner, C., Kandeler, E., and Rethemeyer, J.: Which are important soil parameters influencing the spatial heterogeneity of ${ }^{14} \mathrm{C}$ in soil organic matter?, Biogeosciences Discuss. [preprint], https://doi.org/10.5194/bg-2016-11, 2016.

Jordan, H. and Schwartau, W.: Das Lößprofil von Ahlshausen und weitere tiefe Quartäraufschlüsse entlang der Bundesbahn- 
Neubaustrecke bei Northeim, Südniedersachsen, Quat. Sci. J., 43, 110-122, 1993.

Kieft, T. L. and Rosacker, L. L.: Application of respiration-and adenylate-based soil microbiological assays to deep subsurface terrestrial sediments, Soil Biol. Biochem., 23, 563-568, 1991.

Kirfel, K., Leuschner, C., Hertel, D., and Schuldt, B.: Influence of Root Diameter and Soil Depth on the Xylem Anatomy of Fineto Medium-Sized Roots of Mature Beech Trees in the Top- and Subsoil, Front Plant. Sci., 8, 1194, https://doi.org/10.3389/fpls.2017.01194, 2017.

Kögel-Knabner, I., Guggenberger, G., Kleber, M., Kandeler, E., Kalbitz, K., Scheu, S., Eusterhues, K., and Leinweber, P.: Organo-mineral associations in temperate soils: Integrating biology, mineralogy, and organic matter chemistry, J. Plant Nutr. Soil Sc., 171, 61-82, 2008.

Krumholz, L. R., McKinley, J. P., Ulrich, G. A., and Suflita, J. M.: Confined subsurface microbial communities in Cretaceous rock, Nature, 386, 64-66, 1997.

Libby, W. F.: Radiocarbon Dating, Soc. Am. Archaeol., 132, 621629, 1952.

Litt, T., Behre, K.-E., Meyer, K.-D., Stephan, H.-J., and Wansa, S.: Stratigraphische Begriffe für das Quartär des norddeutschen Vereisungsgebietes, Quat. Sci. J., 56, 7-65, 2007.

Magnabosco, C., Lin, L.-H., Dong, H., Bomberg, M., Ghiorse, W., Stan-Lotter, H., Pedersen, K., Kieft, T., Van Heerden, E., and Onstott, T. C.: The biomass and biodiversity of the continental subsurface, Nat. Geosci., 11, 707-717, 2018.

Marin-Spiotta, E., Chaopricha, N. T., Plante, A. F., Diefendorf, A. F., Mueller, C. W., Grandy, A. S., and Mason, J. A.: Long-term stabilization of deep soil carbon by fire and burial during early Holocene climate change, Nat. Geosci., 7, 428-432, 2014.

Mathieu, J. A., Hatté, C., Balesdent, J., and Parent, É.: Deep soil carbon dynamics are driven more by soil type than by climate: a worldwide meta-analysis of radiocarbon profiles, Glob. Change Biol., 21, 4278-4292, 2015.

Murton, J. B., Goslar, T., Edwards, M. E., Bateman, M. D., Danilov, P. P., Savvinov, G. N., Gubin, S. V., Ghaleb, B., Haile, J., and Kanevskiy, M.: Palaeoenvironmental Interpretation of Yedoma Silt (Ice Complex) Deposition as Cold-Climate Loess, Duvanny Yar, Northeast Siberia, Permafrost Periglac., 26, 208-288, 2015,

Nelson, D. W. and Sommers, L.: Methods of soil analysis: Part 2 chemical and microbiological properties, Wiley Online Library, 9, 539-579, 1983

Paul, E., Collins, H., and Leavitt, S.: Dynamics of resistant soil carbon of Midwestern agricultural soils measured by naturally occurring ${ }^{14} \mathrm{C}$ abundance, Geoderma, 104, 239-256, 2001.

Petsch, S., Berner, R., and Eglinton, T.: A field study of the chemical weathering of ancient sedimentary organic matter, Org. Geochem., 31, 475-487, 2000.

Purkamo, L., Kietäväinen, R., Nuppunen-Puputti, M., Bomberg, M., and Cousins, C.: Ultradeep microbial communities at $4.4 \mathrm{~km}$ within crystalline bedrock: implications for habitability in a planetary context, Life, 10, 2, https://doi.org/10.3390/life10010002, 2020.

R Core Team: R: A language and environment for statistical computing, Vienna, Austria, 2018.

Rethemeyer, J., Gierga, M., Heinze, S., Stolz, A., Wotte, A., Wischhöfer, P., Berg, S., Melchert, J., and Dewald, A.: Current sam- ple preparation and analytical capabilities of the radiocarbon laboratory at CologneAMS, Radiocarbon, 61, 1449-1460, 2019.

Richter, D. and Markewith, D.: How deep is soil?, BioScience, 45, 600-609, 1995.

Rumpel, C. and Kögel-Knabner, I.: The role of lignite in the carbon cycle of lignite-containing mine soils: evidence from carbon mineralisation and humic acid extractions, Org. Geochem., 33, 393-399, 2002.

Rumpel, C., Kögel-Knabner, I., and Bruhn, F.: Vertical distribution, age, and chemical composition of organic carbon in two forest soils of different pedogenesis, Org. Geochem., 33, 1131-1142, 2002.

Schenk, J. and Jackson, R.: Mapping the global distribution of deep roots in relation to climate and soil characteristics, Geoderma, 126, 129-140, 2005.

Schiff, S., Aravena, R., Trumbore, S. E., Hinton, M., Elgood, R., and Dillon, P.: Export of DOC from forested catchments on the Precambrian Shield of Central Ontario: clues from ${ }^{13} \mathrm{C}$ and ${ }^{14} \mathrm{C}$, Biogeochemistry, 36, 43-65, 1997.

Schneider, F. and Don, A.: Root-restricting layers in German agricultural soils, Part I: extent and cause, Plant Soil, 442, 433-451, 2019.

Schrumpf, M., Kaiser, K., Guggenberger, G., Persson, T., KögelKnabner, I., and Schulze, E.-D.: Storage and stability of organic carbon in soils as related to depth, occlusion within aggregates, and attachment to minerals, Biogeosciences, 10, 16751691, https://doi.org/10.5194/bg-10-1675-2013, 2013.

Schwab, V. F., Nowak, M. E., Elder, C. D., Trumbore, S. E., Xu, X., Gleixner, G., Lehmann, R., Pohnert, G., Muhr, J., and Küsel, $\mathrm{K}$.: ${ }^{14} \mathrm{C}$-free carbon is a major contributor to cellular biomass in geochemically distinct groundwater of shallow sedimentary bedrock aquifers, Water Resour. Res., 55, 2104-2121, 2019.

Seifert, A.-G., Trumbore, S., Xu, X., Zhang, D., Kothe, E., and Gleixner, G.: Variable effects of labile carbon on the carbon use of different microbial groups in black slate degradation, Geochim. Cosmochim. Ac., 75, 2557-2570, 2011.

Soucemarianadin, L. N., Cecillon, L., Guenet, B., Chenu, C., Baudin, F., Nicolas, M., Girardin, C., and Barre, P.: Environmental factors controlling soil organic carbon stability in French forest soils, Plant Soil, 426, 267-286, 2018.

Soulet, G., Hilton, R. G., Garnett, M. H., Dellinger, M., Croissant, T., Ogrič, M., and Klotz, S.: Technical note: In situ measurement of flux and isotopic composition of $\mathrm{CO}_{2}$ released during oxidative weathering of sedimentary rocks, Biogeosciences, 15, 4087-4102, https://doi.org/10.5194/bg-15-4087-2018, 2018.

Strauss, J., Schirrmeister, L., Wetterich, S., Borchers, A., and Davydov, S.: Grain-size properties and organic-carbon stock of Yedoma Ice Complex permafrost from the Kolyma lowland, northeastern Siberia, Global Biogeochem. Cy., 26, GB3003, https://doi.org/10.1029/2011GB004104, 2012.

Stuiver, M. and Polach, H. A.: Reporting of C-14 data-Discussion, Radiocarbon, 19, 355-363, 1977.

Swanson, S. K., Bahr, J. M., Bradbury, K. R., and Anderson, K. M. J. S. G.: Evidence for preferential flow through sandstone aquifers in Southern Wisconsin, Sediment. Geol., 184, 331-342, 2006.

Torn, M., Swanston, C., Castanha, C., and Trumbore: Storage and turnover of organic matter in soil, Biophysico-Chemical Processes Involving Natural Nonliving Organic Matter in Environ- 
mental Systems, John Wiley \& Sons Inc, Hoboken, USA, 219_ 272, 2009.

Trumbore, S.: Radiocarbon and soil carbon dynamics, Annu. Rev. Earth Planet. Sc., 37, 47-66, 2009.

Tückmantel, T., Leuschner, C., Preusser, S., Kandeler, E., Angst, G., Mueller, C. W., and Meier, I. C.: Root exudation patterns in a beech forest: dependence on soil depth, root morphology, and environment, Soil Biol. Biochem., 107, 188-197, 2017.

van der Voort, T. S., Mannu, U., Hagedorn, F., McIntyre, C., Walthert, L., Schleppi, P., Haghipour, N., and Eglinton, T. I.: Dynamics of deep soil carbon - insights from ${ }^{14} \mathrm{C}$ time series across a climatic gradient, Biogeosciences, 16, 3233-3246, https://doi.org/10.5194/bg-16-3233-2019, 2019.

Vindušková, O., Sebag, D., Cailleau, G., Brus, J.. and Frouz, J.: Methodological comparison for quantitative analysis of fossil and recently derived carbon in mine soils with high content of aliphatic kerogen, Org. Geochem., 89, 14-22, 2015.

Wagner, B.: Spatial analysis of loess and loess-like sediments in the Weser-Aller catchment (Lower Saxony and Northern Hesse, NW Germany), E\&G Quaternary Sci. J., 60, 3, https://doi.org/10.3285/eg.60.1.02, 2011.
Wang, X., Cammeraat, L. H., Wang, Z., Zhou, J., Govers, G. and Kalbitz, K.: Stability of organic matter in soils of the Belgian Loess Belt upon erosion and deposition, Eur. J. Soil Sci., 64, 219-228, 2013.

Wang, Y., Amundson, R., and Trumbore, S.: Radiocarbon dating of soil organic matter, Quat. Res., 45, 282-288, 1996.

Waschkies, C. and Huttl, R. F.: Microbial degradation of geogenic organic C and N in mine spoils, Plant Soil, 213, 221-230, 1999.

Wordell-Dietrich, P., Don, A., and Helfrich, M.: Controlling factors for the stability of subsoil carbon in a Dystric Cambisol, Geoderma, 304, 40-48, 2017.

Wordell-Dietrich, P., Wotte, A., Rethemeyer, J., Bachmann, J., Helfrich, M., Kirfel, K., Leuschner, C., and Don, A.: Vertical partitioning of $\mathrm{CO} 2$ production in a forest soil, Biogeosciences, 17, 6341-6356, https://doi.org/10.5194/bg-17-6341-2020, 2020.

WRB, I. W. G.: Food and Agriculture Organization of the United Nations, Rome, Italy, 145 pp., 2006.

Zethof, J. H. T., Leue, M., Vogel, C., Stoner, S. W., and Kalbitz, K.: Identifying and quantifying geogenic organic carbon in soils - the case of graphite, SOIL, 5, 383-398, https://doi.org/10.5194/soil-5-383-2019, 2019. 